The study of freshwater pelagic communities is entering an exciting and controversial phase. Recent efforts to clarify how food web interactions differ from food chain interactions have emphasized the various, often subtle, repercussions of top predators on communities. Predators can modify community structure not only through directly imposed death rates, but also through direct and indirect effects on prey interactions, behavior, life-styles and morphology (e.g. induction of defenses). In some cases, the effects influence ecosystem properties (material fluxes, turnover rates and primary production). Attempts to trace food web impacts in enclosure and lake studies have revealed important timedependent system properties. Severe resource limitation of fast variables (phytoplankton and small zooplankton) stabilizes lower trophic levels, whereas the potentially destabilizing effects of fish population oscillations are long compared to the growing season and subject to year-to-year climatic vagaries. The time-scale dependent approach is important because it emphasizes how local (transient) solutions may be more ecologically relevant to stability calculations than overall (global) solutions.

Traditional approaches to aquatic food webs (i.e. phytoplanktonzooplankton-fish links) focus attention on specific trophic levels, allowing investigators to concentrate on interaction rates within a single order of magnitude. By slicing up trophic webs into horizontal or limited vertical strata, workers on nutrient-phytoplankton, phytoplankton-grazer, and zooplankton-fish interactions can become experts on particular taxonomic groups and gain substantial insights into the pattern and strengths of species-specific interactions $^{1-3}$.

Recent investigations at the base of food webs, the picoplankton-flagellate-ciliate interactions termed 'microbial loops' follow similar tactics by isolating subsystems with limited ranges of fast rates. Yet to what extent does this specialized subdivision divert

W.C. Kerfoot is at the Center for Great Lakes and Aquatic Sciences and the Dept of Biology, College of Literature, Science, and the Arts, The University of Michigan, Ann Arbor, MI 48109, USA; D.L. DeAngelis is in the Environmental Sciences Division, Oak Ridge National Laboratory, Oak Ridge, TN 37831, USA.

\title{
Scale-dependent Dynamics: Zooplankton and the Stability of Freshwater Food Webs
}

\author{
W. Charles Kerfoot and D.L. DeAngelis
}

attention from important wholesystem properties, in particular, strongly stabilizing interactions at the base of pelagic food webs and scale-dependent equilibrium dynamics 5 ?

Entire pelagic food webs have received increased attention lately 6,7 , with a two-fold aim: (1) to organize information on community interactions and ecosystem processes in a way that is both informative and manageable, and (2) to handle ecosystem process rates that differ by at least 5-6 orders of magnitude, from nutrient fluxes to fish demographics, within a realistic context that includes natural perturbations and variability $^{8}$. From a historical perspective, the efforts ultimately seek to fuse selective predation concepts (e.g. Brooks-Dodson size efficiency hypothesis) ${ }^{9}$ with Lindeman's trophic-dynamic scheme ${ }^{10}$.

Community studies have revealed some important general properties of temperate pelagic food webs:

(1) Introduction of planktivorous fish usually has profound effects on zooplankton communities, excluding and suppressing large-bodied zooplankters, especially Daphnia.

(2) Competitive interactions among grazers can be strong, with large Daphnia suppressing smallerbodied species (cladocerans, copepods and rotifers) ${ }^{11}$.

(3) Moderate levels of fish predation can indirectly benefit smaller-bodied grazers and certain predatory invertebrates, whereas high levels are often inhibitory.

(4) Fish and invertebrate predators can induce defensive behavioral and morphological adjustments in prey, responses that modify spatial and temporal interactions

(5) Increased densities of Daphnia often coincide with increased water transparency and reduced phytoplankton concentrations.

Much of the discussion centers on the dual elements of food web interactions, the so-called top-down versus bottom-up components $^{12}$, that reflect the energetic benefit gained by the consumer and the simultaneous loss suffered by the resource (Fig. 1) ${ }^{13}$ Controversial issues include the extent to which limiting nutrients determine productivity at all levels, food chain length and community composition, versus the extent to which biased foraging increases or decreases potential productivity, influences local community composition, excludes certain prey and determines the branching pattern of food webs.

\section{Theoretical models and empirical} observations

Pioneering efforts have aimed at understanding scatter in freshwater Vollenweider curves, i.e. curves used for prediction of chlorophyll or productivity from phosphorus loading ${ }^{14}$. Certain models, such as those of Oksanen ${ }^{15}$ and Walters et al. ${ }^{16}$, essentially contrast the relationship between expected and realized phytoplankton biomass versus nutrient input or potential primary productivity.

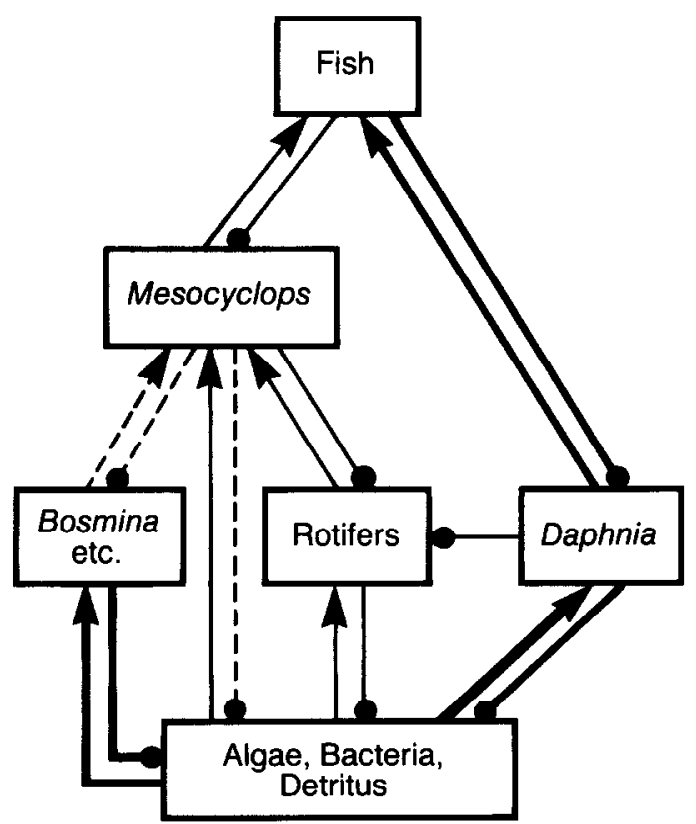

Fig. 1. Basic components of a lake community (Lake Mitchell, Vermont, USAI, illustrating the dual nature of trophic interactions. Positive effects indicated by arrows, negative effects by closed circles ${ }^{21}$ 


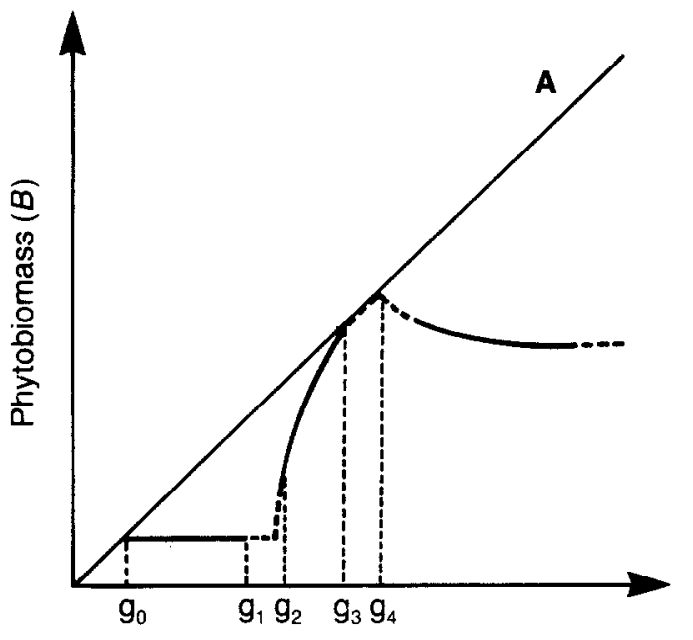

Potential primary productivity $(G)$

Fig. 2. The relationship between potential primary productivity $(G)$ and phytobiomass $(B)$ for a one to four trophic-level system based on Ref. 15. Line A shows the relationship between $G$ and $B$ in the absence of other trophic levels. For very low $G$ values phytobiomass will increase linearly with $G$ up to a level where phytobiomass is high enough to maintain grazers in the system $\left(G<\mathrm{g}_{0}\right)$. A further increase in $G$ will give no response in phytobiomass but only an increase in grazer biomass $\left(\mathrm{g}_{0}-\mathbf{g}_{1}\right)$. If $G$ continues to increase, in systems with a high ecological efficiency, the s:stem may become destabilized so that sustained oscillations are to be expected $\left(g_{1}-g_{2}\right)$. A further increase in $G$ will lead to the primary carnivore isocline being passed and an unstable plant-grazer-primary producer equilibrium point is established $\left(g_{2}-g_{3}\right)$. With a further increase in $G$ this equilibrium point will be stabilized $\left(g_{3}-g_{4}\right)$. In aquatic systems with a high ecological efficiency a fourth trophic level - secondary carnivores - might be able to invade the system $\left|G>g_{4}\right|$. The effect of a secondary carnivore is to regulate primary carnivores, and an increase in $G$ in these systems, therefore, should result only in an increase in biomass of secondary carnivores and herbivores and not in primary carnivores and phytobiomass. In fact, phytobiomass is predicted to decline somewhat, especially at the transition from three- to four-link dynamical structure ${ }^{39}$

Unfortunately, the Oksanen model (Fig. 2), a more analytical version of the original Hairston, Smith and Slobodkin argument, suffers from two serious deficiencies: (1) it is a food chain model rather than a food web model, and hence fails to emphasize many kinds of indirect effect, and (2) it fails to incorporate resource quality responses, e.g. inedibility of certain primary producers.
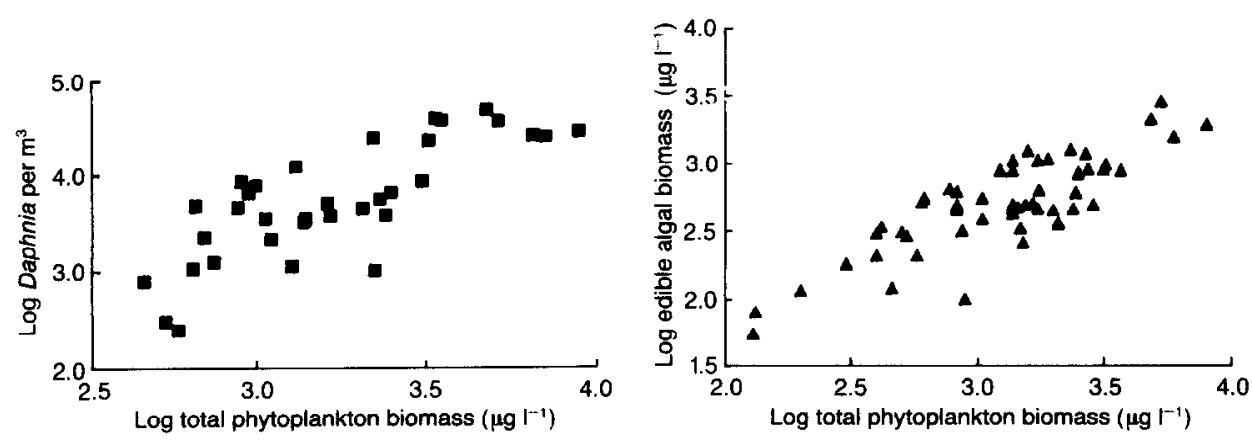

Fig. 3. Empirical observations of trends in Daphnia density (left) and accessible $(>50 \mu \mathrm{m}$ length) algal biomass (right) across a gradient of total phytoplankton biomass ${ }^{22}$.

The food chain structure predicts a characteristic saw-toothed pattern over a gradient of increasing nutrient input (Fig. 2). However, empirical data on plant and animal trends across nutrient gradients show more gradual, less saw-toothed patterns (Fig. 3), with plant biomass in reasing relative to animal biomass.

Regression studies of successive trophic levels have revealed interesting trends along the productivity gradient, seemingly indicating progressive reduction of regression slopes and lower correlations for higher trophic levels (Fig. 4l, although the causal relationships are unclear.

Changes in resource quality as a consequence of foraging or nutrient ratios have implications for the system. Terrastrial and aquatic studies show that many morphological and chemical traits of resources reduce the effectiveness of consumption For example, certain algae are inaccessible to grazers because of size, whereas others are protected by spines, sheaths or noxious compounds ${ }^{17-19}$. Protozoans, rotifers and cladocerans may possess defensive helmets, spikes and body protrusions that lower consumption rates by predators ${ }^{20}$. The net effect is that inaccessibility and resistance lower potential energy flow to higher trophic levels making consumers as a group more resource-limited. Models that incorporate inedibility and inaccessibility produce better fits with observed patterns ${ }^{16,21,22}$

\section{Time-scale dependent models}

Time-scale considerations present some of the most intriguing and perplexing dilemmas for analysis of food web responses. Arguments against equilibrium models come from some workers at both the bottom and top of food webs.
One view in temperate lake studies is that algal and zooplankton communities are subject to seasonal changes that occur so rapidly as to preclude the establishment of any equilibrium ${ }^{23}$. Another view argues that because fish possess long generation times and show sensitivity to climatic variables, long-term stability is unrealistic. However, examination of such models reveals that, while the pelagic web as a whole may be constantly changing through time, certain rapidly responding categories (e.g. edible phytoplankton, total Daphnia) may be in relative equilibrium with each other. This equilibrium changes with the seasons and with longterm changes in the variables that respond slowly (Box 1), that is, the dynamics are very timedependent. The time-dependent approach has both practical and intuitive appeal, because it forces us to consider the time frame of whole system responses and prompts us to clarify the meaning of 'top-down' versus 'bottom-up' interactions.

The Jacobian matrix A described in Box 1 reflects two important aspects of food web behavior. First, the direction of propagation of effects of a perturbation, from higher levels downwards or vice versa, is indicated by the relative sizes of the elements $a_{f i}$ in the matrix array.

Elements above the diagonal $(j>i)$ indicate receptor dependence of the interaction between the populations $i$ and $j$, whereas elements below the diagonal $(j<i)$ indicate donor dependence of the interaction. The receptor dependence generally indicates a topdown effect of perturbation, while donor dependence indicates that a perturbation will propagate from lower to higher levels. In general, receptor-controlled systems are less stable than donor-controlled systems, thus offering insights into stability behavior.

Although totally donor-controlled and receptor-controlled systems can be imagined, most natural systems contain a mixture of controls, and the Jacobian has non-zero elements on both sides of the diagonal. That is, in most real systems, effects propagate in both directions (Table 1), but the occurrence of resources that are resistant 

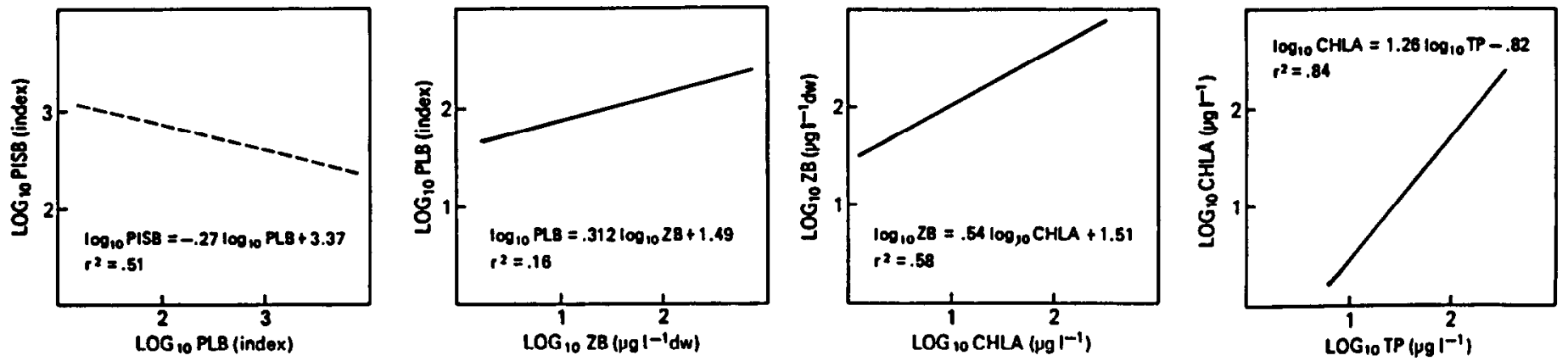

Fig. 4. Mean regression lines for empirical data, comparing various trophic levels. TP, total phosphorus; CHLA, chlorophyll a, a standard index of phytoplankton biomass; ZB, zooplankton biomass (dry weight); PLB, planktivorous fish biomass index, based on catch per unit effort; PISB, piscivorous fish biomass index, based on catch per unit effort ${ }^{12}$.

to consumption can shift the interaction in the direction of donor control, so that the dominant influence is from the lower level upwards.

Second, the time-scales of dynamics (responses to and recovery from perturbations) are indicated by the sizes of the eigenvalues $\left(\lambda_{j}\right)$ of Eqn 3 (Box 1$)^{24,25}$. Positive values of $\lambda_{R i}$ indicate instability and limit-cycle oscillations. Negative values of $\lambda_{R j}$ indicate stability, and the size of each $\left|\lambda_{R i}\right|$ in this case represents a characteristic timescale $\left(t_{j}\right)$ of return to equilibrium. Large values of $\left|\lambda_{R j}\right|$ indicate a rapid return while small values indicate a slow return.

The existence of $n$ eigenvalues describing an n-component system expresses in a formal way that one system may display behavior on several time-scales. Consider a hypothetical system for which $\lambda_{\mathbf{R} 1}=$ 0.001 per year and $\lambda_{11}=0.5$ per year, whereas the other real parts of the eigenvalues are all negative and $\lambda_{R i}<-10.0$ per year $(j>1)$. This set of eigenvalues reflects dynamics occurring at very different timescales: a slow limit-cycle oscillation with a period of about $2 \pi / 0.5=12.6$ years, and stable transient dynamics with characteristic time-scales of about a month or less. Over a period of a few months (say, a typical growing season), the $\mathrm{dy}$ namics due to a long time-scale limit cycle would be imperceptible and only the stable transient dynamics would be important.

Thus, stability is time-scale dependent or 'temporally local'. Unstable behavior on long timescales may not be reflected in system behavior on short timescales, which might be quite stable. Systems in which more than a single time-scale occurs are termed 'multiple time-scale' or 'stiff' systems, the latter term arising from engineering modeling.
Stiffness is also relative, with the ratio, min $\left(\lambda_{R j}\right): \max \left(\lambda_{R j}\right)$, serving as a measure of stiffness. The property of stiffness seems inherent to the dynamics of most pelagic food web models. For example, phosphate uptake rates are traditionally expressed on a scale of seconds to minutes, bacterial doubling times in hours, phytoplankton and small zooplankton generation times in days, predatory invertebrate lifespans in months, and fish dynamics in years or decades.

\section{Example of a time-dependent system}

Because ponds and lakes are clearly defined, bounded ecosystems amenable to experimental manipulation, with easily quantifi- able inputs and outputs, pelagic food webs offer excellent opportunities for joint community/ ecosystem studies. Sandwiched between fish and phytoplankton in these webs are the zooplankton, a heterogeneous assemblage of herbivores, omnivores and invertebrate predators that ultimately draw energy from primary producers and bacteria, yet serve as essential forage items for fish during crucial recruitment stages.

Formal stability analysis of a specific case (Lake Mitchell, Fig. 1) indicated that the midsummer community was stable, and that strongly stabilizing interactions were concentrated at the base of the food web ${ }^{7,26}$. The ratio of time

\section{Box 1. Time-dependent community models}

In order to illustrate how time dependence enters into community models, consider a general model of interactions between $n$ food web components, $N_{j}$. One assumption is that the interactions can be described by a set of first-order ordinary differential equations.

$$
\mathrm{d} N_{i} / \mathrm{d} t=\mathrm{f}_{1}\left(N_{1}, N_{2}, \ldots N_{n}\right)
$$

which are nonlinear in general. The system of equations may have one or more steady-state equilibrium points, where the stability of a given equilibrium point can be analysed by linearizing the system about the equilibrium point $\mathbf{N}^{*}=\left(N_{1}^{*}, N_{2}^{*}, \ldots, N_{n}^{*}\right)$ to obtain a set of linear equations.

$$
\mathrm{d} \mathbf{N}_{\mathrm{T}}(t) / \mathrm{d} t=A \mathbf{N}_{\mathrm{T}}(t)
$$

where $\mathbf{N}_{\mathrm{T}}(t)$ is the transpose of the vector $\mathbf{N}(t)=\left(N_{1}(t), N_{2}(t), \ldots N_{n}(t)\right)$ and $A$ is the Jacobian matrix, whose elements $\left(a_{i j}\right)$ are constants:

$$
A=\left|\begin{array}{cccc}
a_{11} & a_{12} & \ldots & a_{1 n} \\
a_{21} & a_{22} & \ldots & a_{2 n} \\
\cdot & & & \\
\cdot & & & \\
\cdot & & & \\
a_{n 1} & a_{n 2} & \ldots & a_{n n}
\end{array}\right|
$$

The solution of Eqn 2 is a summation of the form

$$
\mathbf{N}(t)=\mathbf{N}^{*}+\sum_{j=1}^{n} \mathbf{C}_{i} e^{\lambda_{j} t}
$$

where the terms $C_{i}$ and $\lambda_{j}$ are constants

This solution often reveals that the dynamics of pelagic systems occur on two or more distinct time-scales. On the short time-scale, the more rapidly responding variables (e.g. zooplankton and phytoplankton) quickly move toward a relative equilibrium in the system within a season. However, the relative equilibrium is not a constant, but may vary over longer time periods. Slowly changing components, such as populations of long-lived fish, can produce long-period oscillations. Technically, these short and long time-scale behaviors are described by so-called 'eigenvalues' or complex time constants, $\lambda_{j}=\lambda_{R j}+i \lambda_{1 j}$ (where $\lambda_{R /}$ is the real part and $i \lambda_{1}$ the imaginary part), which are associated with a particular Jacobian matrix $A$.

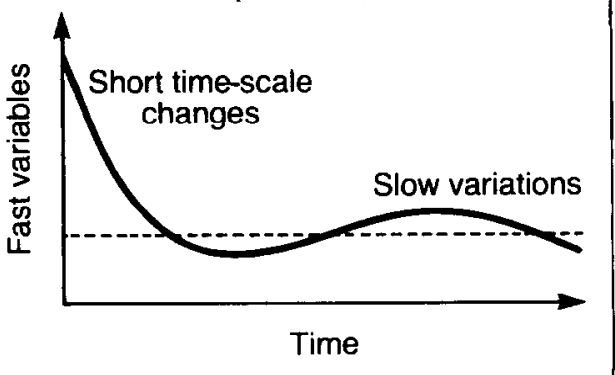


Table 1. Elements in the Jacobian matrix for the Lake Mitchell (Vermont, USA) food weba.

\begin{tabular}{lcccccc}
\hline & \multicolumn{7}{c}{ Effect of: } \\
\cline { 2 - 7 } & Flagellates & Resistants & Daphnia & Bosmina & Mesocyclops & Fish \\
\hline \multicolumn{1}{c}{ Effect on: } & & & & & \\
Flagellates & $a_{11}$ & $a_{12}$ & $a_{13}$ & $a_{14}$ & $a_{15}$ & $a_{16}$ \\
Resistants & $a_{21}$ & $a_{22}$ & $a_{23}$ & $a_{24}$ & $a_{25}$ & $a_{26}$ \\
Daphnia & $a_{31}$ & $a_{32}$ & $a_{33}$ & $a_{34}$ & $a_{35}$ & $a_{36}$ \\
Bosmina & $a_{41}$ & $a_{42}$ & $a_{43}$ & $a_{44}$ & $a_{45}$ & $a_{46}$ \\
Mesocyclops & $a_{51}$ & $a_{52}$ & $a_{53}$ & $a_{54}$ & $a_{55}$ & $a_{56}$ \\
Fish & $a_{61}$ & $a_{62}$ & $a_{63}$ & $a_{64}$ & $a_{65}$ & $a_{66}$ \\
\hline Flagellates & -0.137 & -0.046 & -0.307 & -1.07 & -0.02 & 0.00 \\
Resistants & -0.088 & -0.087 & -0.102 & -0.00 & -0.01 & 0.00 \\
Daphnia & +0.20 & +0.066 & -0.02 & 0.00 & 0.00 & -0.006 \\
Bosmina & +0.06 & +0.00 & 0.00 & 0.00 & -0.05 & 0.00 \\
Mesocyclops & +0.02 & +0.01 & 0.00 & +0.002 & 0.00 & -0.006 \\
Fish & 0.00 & 0.00 & +0.0012 & 0.000 & +0.0012 & -0.002 \\
\hline
\end{tabular}

alnteraction coefficients are presented in the upper part of the Table, estimated values in the lower part ${ }^{26}$. In the solutions for this matrix, all eigenvalues are negative, indicating a stable system $(\lambda=-0.0926 \pm 0.280 \mathrm{i},-0.0050,-0.0094,-0.0230 \pm 0.023 \mathrm{i})$. The imaginary portions (i) reveal oscillatory dynamics, with the ratio of eigenvalues ( $\max \lambda / \min \lambda=18.5$ ) indicating stiff system dynamics.

constants exceeded several orders of magnitude 27 , making the food web model a stiff system, a result in agreement with several other general models of nutrient-phyto-

plankton-grazer dynamics 28,29 . This meant that intrinsic oscillations of the entire system were on a long enough time-scale (several years) that they were not noticeable with-

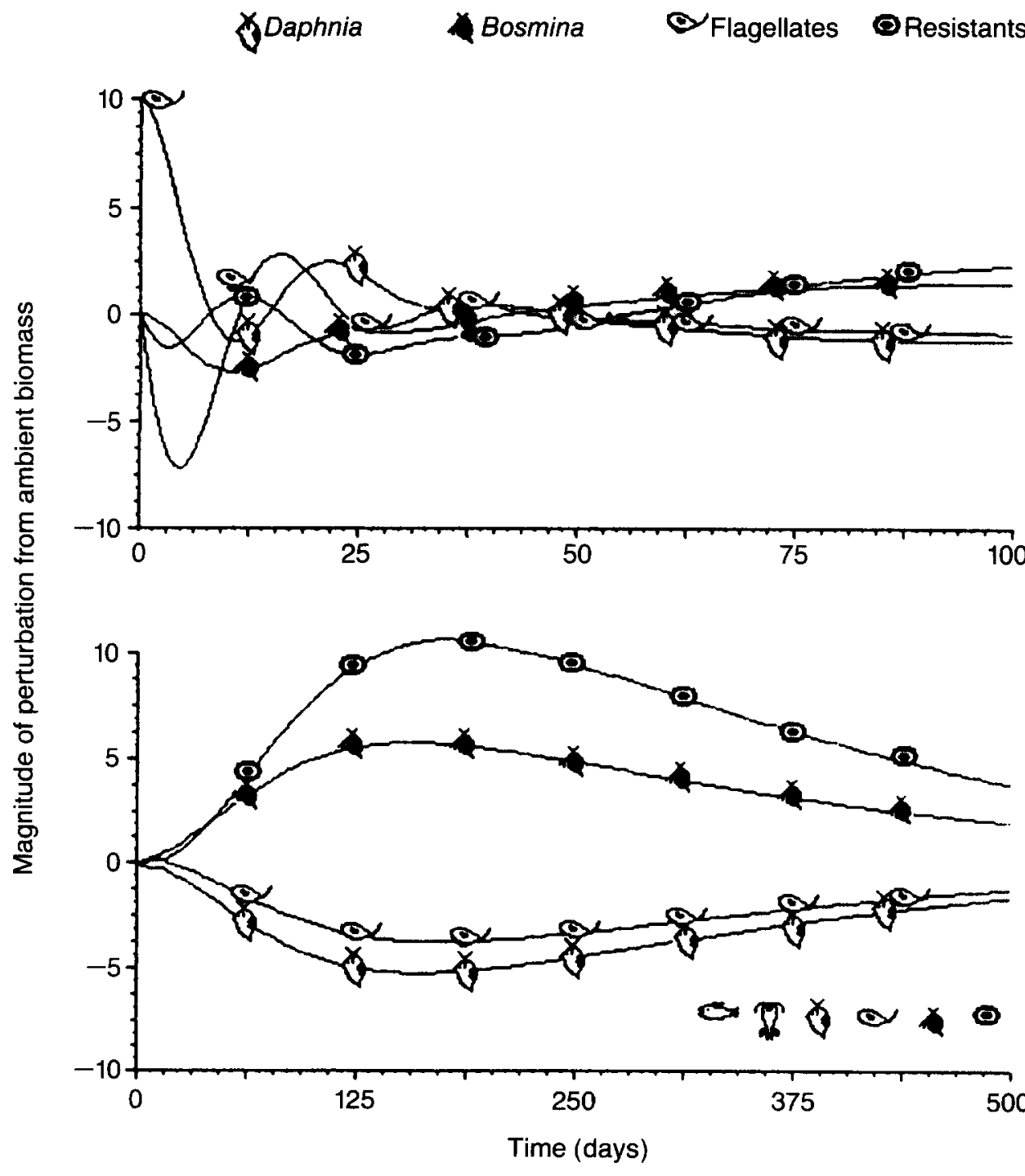

Fig. 5. Responses in the Lake Mitchell food web model caused by equal biomass perturbations of edible algae (above) and fishes (below). Note the time-scale difference in the responses ${ }^{27}$. in a particular growing season.

Perturbation experiments confirmed the strongly stabilizing effects of resource limitation at the bottom of the food web ${ }^{21}$. Artificially perturbed phytoplankton and zooplankton populations returned quickly to initial levels, resembling the general time course and magnitude of model predictions (Fig. 5), although there were some specific deviations. A key genus in these interactions was the competitive dominant, the cladoceran Daphnia, whose inclusive dietary overlaps with a number of smaller-bodied zooplankton species create numerous indirect effects through resource limitation.

If pelagic food webs contain inherently stiff dynamics, what are the practical consequences? When rates differ by orders of magnitude, there are some convenient simplifications that are good approximations of overall dynamic solutions. Fast variables, such as nutrient uptake kinetics, can be incorporated into slow variables by converting fast indirect interactions into quasi-direct interactions. Such abstractions, that reduce dimensions by folding fast variables into slower dynamics, can preserve certain dynamic responses ${ }^{30}$. Alternatively, if the time frame emphasizes transient dynamics, slow variables may be treated as constants ${ }^{31}$. The latter arrangement has great advantages for enclosure perturbation experiments ${ }^{24}$, because nutrient, phytoplankton and small zooplankton responses are frequently much more rapid than fish responses.

\section{Abiotic and biotic perturbations}

Climatic variables, such as seasonality, may restrict the applicability of steady-state conditions to limited intervals. For example, in temperate lakes, the seasonal context of interactions is crucial because the nutrient-phytoplankton assemblage undergoes such strong temporal changes. Usually a spring phytoplankton community of small, fast-growing algae (e.g. Cryptophyceae, small centric diatoms). stimulated by winter nutrients, precedes a summer community more strongly influenced by internal nutrient cycling and intensified grazer interactions ${ }^{32,33}$. As nutrients become more limiting to phytoplankton population growth, algal turn- 
over rates decline to the point where dynamics become more sensitive to grazer influence. At the same time, if not subject to limitation by their own enemies, largebodied herbivores increase exponentially until their combined density may be sufficient to produce a significant community filtration rate.

In temperate lakes where the spring phytoplankton bloom is composed of small, highly edible species, the initial grazer-phytoplankton interactions resemble the first cycle of classic predatorprey laboratory experiments. The cropping rate may result in a noticeable 'clear water' phase, followed by Daphnia decrease, prior to summer nutrient-limited conditions $^{32}$. Thereafter, resistant or inaccessible algae contribute greatly to the observed phytoplankton biomass.

The late spring to early fall 'window' of nearly stable nutrientlimited conditions potentially extends only over a period of about 120 days, too short for population responses of some large predatory invertebrates and fishes in temperate lakes (Figs 1 and 5). Large invertebrate predators, such as Chaoborus or Mysis, and fishes could carry over dynamics to the next year, driving long-term oscillations, if not severely modified by weather.

Within this summer window, severe resource limitation of phytoplankton communities generally is acknowledged ${ }^{34}$. This restriction is confirmed by only modest increases in phytoplankton biomass when grazers are removed from enclosures. Resource limitation of zooplankton is determined indirectly by noting reductions in per capita fecundity related to density and directly through manipulation of animals and resources in enclosure experiments ${ }^{9,19}$.

\section{Long-term effects of fish}

Long-term monitoring studies of fish effects on pelagic food webs are scarce ${ }^{16,35}$. Fortunately, some zooplankton remains preserve well in lake sediments, offering a longterm record of events. The few cases that have been analysed for predation effects have revealed substantial patterns in the effects of both invertebrates and fish over decades to thousands of years ${ }^{36-38}$. Clearly more effort is needed in this area to clarify the extent to which climate modifies demographic carry-over of slow variables from year to year.

\section{Acknowledgements}

WCK acknowledges the National Science Foundation's past support (DEB 80-04654 DEB 82-07007 and BSR-8400244); DLD acknowledges partial support from NSF's Ecosystem Studies Program (Interagency Agreement No. 40-689-78 with Martin Marietta Energy Systems, Inc., under contract DE-AC05-840R21400 with the US Dept of Energy). We thank Gary Belovsky, John Lehman, Susan Kilham, Earl Werner and Matthew Leibold for helpful suggestions.

\section{References}

1 Tilman, D. (1982) Resource Competition and Community Structure, Princeton University Press

2 DeMott, W.R. in Plankton Ecology: Succession in Plankton Communities (Sommer, U., ed.), Science Tech Press (in press)

3 Werner, E.E., Gilliam, I.F., Hall, D.J. and

Mittebach, G.G. (1983) Ecology 64, 1540-1548 4 Pomeroy, L.R. and Wicke, W.J. (1987)

Hydrobiologia 159, 7-18

5 O'Neill, R.V., DeAngelis, D.L., Waide, I.B. and Allen, T.F.H. (1986) A Hierarchical Concept of Ecosystems, Princeton University Press

6 Kerfoot, W.C. and Sih, A., eds (1987)

Predation: Direct and Indirect Impacts on

Aquatic Communities, University Press of

New England

7 Carpenter, S.R., ed. (1988) Complex

Interactions in Lake Communities, SpringerVerlag

8 Carpenter, S.R. and Kitchell, J.F. (1987) Am. Nat. 129, 417-483

9 Brooks, I.L. and Dodson, S.I. (1965) Science $150,28-35$

10 Lindeman, R.L. (1942) Ecology 23, 399-418 II Gilbert, I.J. (1988) Limnol. Oceanogr. 33. 1286-1303

12 McQueen, D.J., Post, I.R. and Mills, E.L. (1986) Can. J. Fish. Aquat. Sci. 43, 1571-1581 13 Kerfoot, W.C. (1987) in Predation: Direct and Indirect Impacts on Aquatic

Communities (Kerfoot, W.C. and Sih, A., eds), pp. 57-70, University Press of New England 14 Shapiro, I. (1980) in Hypertrophic

Ecosystems (Barica, J. and Mur, L., eds), pp. 105-115, W. Junk

15 Oksanen, L.S., Fretwell, D., Arruda, I. and Niemela, P. (1981) Am. Nat. 188, 240-261 16 Walters, C.J., Krause, E., Neill, W.E. and Northcote, T.G. (1987) Can. I. Fish. Aquat. Sci. 44, 1002-1017

17 Porter, K.G. (1973) Nature 244, 179-180

18 Lehman, J.T and Sandgren, C. (1985)

Limnol. Oceanogr. 30, 34-46

19 Sterner, R.W. in Plankton Ecology: Succession in Plankton Communities (Sommer, U., ed.), Science Tech Press (in press)

20 Havel, J.E. (1987) in Predation: Direct and Indirect Impacts on Aquatic Communities (Kerfoot, W.C. and Sih, A., eds), pp. 263-278, University Press of New England

21 Kerfoot, W.C., Levitan, C. and DeMott,

W.R. (1988) Ecology 69, 1806-1825
22 McCauley, E., Murdoch, W.W. and Watson, S. (1988) Am. Nat. 132, 383-403

23 Harris, G.P. (1986) Phytoplankton Ecology: Structure, Function and Fluctuation.

Chapman $\&$ Hall

24 Bender, E.A., Case, T.J. and Gilpin, M.E. (1984) Ecology 65, 1-13

25 May, R.M. (1973) Stability and Complexity in Model Ecosystems, Princeton University Press

26 Levitan, C. (1987) In Predation: Direct and Indirect Impacts on Aquatic Communities

(Kerfoot, W.C. and Sih, A., eds), pp. 71-100, University Press of New England

27 Levitan, C. and Kerfoot, W.C. (1987) Ecol. Soc. Am. Abstr.

28 Hallam, T.G. (1978) J. Math. Biol. 5 ,

$261-280$

29 Arnold, E.M. and Voss, D.A. $(1981)$ Ecol Model. 13, 183-193

30 Schaffer, W.M. (1981) Ecol. Monogr. 51 , 383-40 I

31 DeAngelis, D.L. and Waterhouse, J.C (1987) Ecol. Monogr. 57, 1-21

32 Sommer, U., Gliwicz, Z.M., Lampert, W. and Duncan, A. (1986) Arch. Hydrobiol. 106, 433-471

33 Tilman, D., Kilham, S.S. and Kilham, P. (1982) Annu. Rev. Ecol. Syst. 13, 349-372 34 Reynolds, C.S. (1984) The Ecology of Freshwater Phytoplankton, Cambridge University Press

35 Mills, E.L., Forney, J.L. and Wagner, K.] (1987) in Predation: Direct and Indirect Impacts on Aquatic Communities (Kerfoot, W.C. and Sih, A., eds), pp. 118-131, University Press of New England 36 Kerfoot, W.C. (1981) Ecology 62, 216-233 37 Kitchell, J.A. and Kitchell, J.F. (1980)

Limnol. Oceanogr. 25, 389-402

38 Kitchell, J.F. and Carpenter, S.R. (1987) in Predation: Direct and Indirect Impacts on Aquatic Communities (Kerfoot, W.C. and Sih A., eds), pp. 132-146, University Press of New England

39 Persson, L., Andersson, G., Hamrin, S.F. and Johansson, L. (1988) in Complex

Interactions in Lake Communities

(Carpenter, S.R., ed.), 45-65, Springer-Verlag

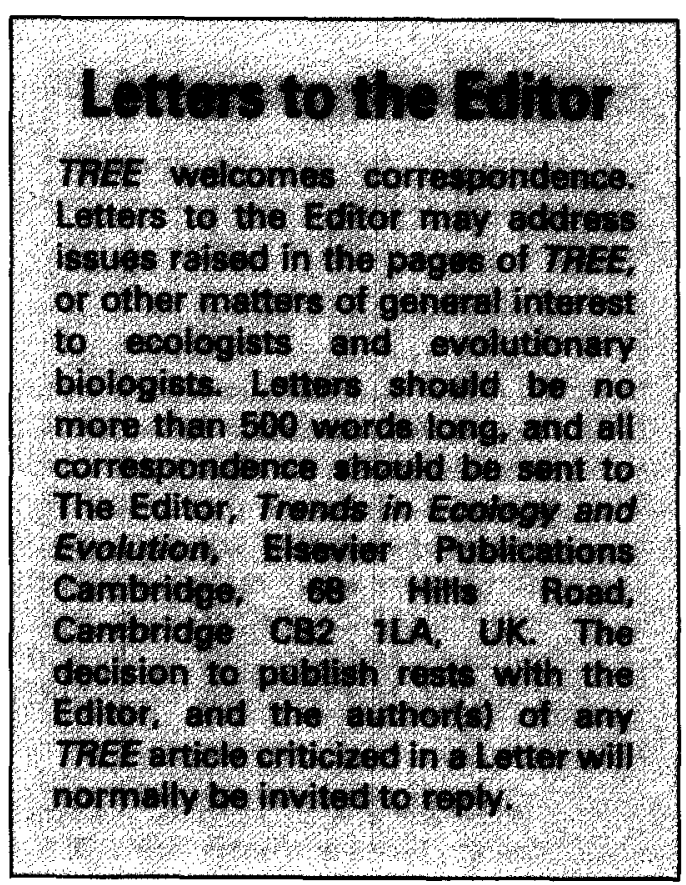

